\title{
APLICAÇÃO DE MISTURAS DE DIURON COM MSMA, E COM PARAQUAT, NO CONTROLE DE PLANTAS DANINHAS DE FOLHAS LARGAS EM CULTURA DE ALGODÃO (Gossypium hirsutum L.)
}

\author{
L. S. P. CRUZ * \& L. LEIDERMAN ** \\ * Eng ${ }^{0} \mathrm{Agr}^{0}$ Pesquisador Científico, Bolsista do \\ CNPq. \\ ** Eng ${ }^{0}$ Agre Pesquisador Científico Chefe. \\ Seção de Herbicidas, Ins tituto Biológico -- \\ 13.100 - Campinas, SP. \\ Trabalho apresentado na 29.a Reunião Anual \\ da SBPC, São Paulo, julho, 1977. \\ Recebido para publicação em 12 de setembro \\ de 1977.
}

\section{RESUMO}

Em ensaio de campo conduzido em 1975/76 procurou-se avaliar a ação de misturas de MSMA com diuron e de paraquat com diuron, aplicadas em pós-emergência, em jato dirigido, em duas épocas diferentes, no controle de algumas plantas daninhas de folhas largas em algodão: carrapicho-do-campo (Acanthospermum australe (Loef) O. Kuntze) , falsa-poaia (Borreria alata (Aubl) DC), poaia-branca (Richardia brasiliensis Gomez ) e guanxuma (Sida spp) . A vegetação natural da área do ensaio era formada ainda pe la gramínea capim-de-colchão (Digitaria sanguinalis (L.) Scop ).

Os resultados mostraram que as misturas de $2,00 \mathrm{~kg}$ e $2,70 \mathrm{~kg} / \mathrm{ha}$ de MSMA com, respectivamente $0,30 \mathrm{~kg}$ e $0,40 \mathrm{~kg} / \mathrm{ha}$ de diuron, e a mistura de $0.60 \mathrm{~kg} / \mathrm{ha}$ de paraquat com $0,60 \mathrm{~kg} /$ ha de diuron, foram eficientes no controle daquelas dicotiledôneas, e também no da gramínea. Todos os tratamentos provocaram leves sintomas de fitotoxicidade nos algodoeiros, mas desapareceram depois e não prejudicaram o desenvolvimento vegetativo das plantas, assim como a produção de algodão em caroço.

Unitermos: Herbicidas, misturas, controle, dicotiledôneas, algodão.

\section{SUMMARY}

MIXTURE OF DIURON WITH MSMA AND WITH PARAQUAT FOR BROADLEAVED WEEDS CONTROL IN COTTON.
In a field trial carried out in $1975 / 76$, a diu. ron mixture with MSMA and another with paraquat was tested on broadleaved weeds in cotton crops. The applications were done in post emergence, directed-spray, in two different periods. The broadleaved weeds observed in the trial were Acanthos permum australe, Borreria alata, Richardia brasiliensis, and Sida spp, also the grass Digitaria sanguinalis.

Best results were obtained with the mixture of $0,60 \mathrm{~kg} / \mathrm{ha}$ of paraquat with $0,60 \mathrm{~kg} / \mathrm{ha}$ of diuron, and $2,70 \mathrm{~kg} / \mathrm{ha}$ of MSMA with $0,40 \mathrm{~kg} /$ ha of diuron, or $2,00 \mathrm{~kg} / \mathrm{ha}$ of MSMA with 0,30 $\mathrm{kg} /$ ha of diuron.

All the treatments caused slight symptons of toxicity in cotton, which disappeared later and did not damage the production.

Keywords: Herbicides, mixture, control, broadleaved weeds, cotton.

\section{INTRODUÇÃO}

Controlada a infestação de gramíneas por herbicidas altamente eficazes $(6,11,12,13)$ as plantas daninhas de folhas largas tornaramse problema em algodoais. Diversos autores têm mostrado a eficiência da combinação de dois ou mais herbicidas no controle de gramíneas e plantas daninhas de folhas largas. Alves \& Forster (3) estudaram a aplicação de trifluralin e diuron, e suas combinações no controle de plantas daninhas nas primeiras fases da cultura. Leiderman et al. (11) em experimentos também com trifluralin e diuron, 
aplicados em pré-plantio incorporado, mostraram sua eficiência no controle de mono e dicotiledôneas, porém todos os tratamentos precisaram de capinas manuais e mecânicas adicionais, até a época da colheita.

O controle de gramíneas e plantas dani nhas de folhas largas, desde o início da cultura até a colheita, com o emprego de mais do que um herbicida foi amplamente estuda do nos Es tados Unidos, sendo hoje prática comum entre os cotonicultores daquele país. No Brasil, Cruz (7) em ensaios conduzidos em 1973, mostrou as vantagens do uso de misturas de paraquat e diuron, aplicadas em pósemergência, em ja to dirigido, em algo do ei ros tratados com dinitramine, em pré plantio incorporado.

O presente experimento teve por objetivo us ar misturas de herbicidas já formuladas, aplicadas em pós-emergência, para controlar principalmente as plantas daninhas de folhas largas.

\section{MATERIAIS E MÉTODOS}

O experimento foi conduzido no município paulista de Casa Branca com algodoeiros da varied ade IAC-13-1, ai nda em distribuição pela Secretaria da Agricultura do Estado de São Paulo para plantio comercial.

Adotou-se o delineamento experimental de blocos ao acaso com 10 tratamentos e quatro repetições. As parcelas eram formadas por cinco linhas de algodoeiros com 5,00 $\mathrm{m}$ de comprimento, espaçadas de $1,00 \mathrm{~m}$, com área útil de $15,00 \mathrm{~m}^{2}$, formada pelas três linhas centrais.

O algodão foi semeado em 05/11/75, e a primeira aplicação de herbicidas (precoce) foi realizad a a 11/12/75 e a outra (tardia) a 14/01/76.

Tanto na aplicação precoce como na tar dia foram testadas as mi sturas de $1,35 \mathrm{~kg}$, $2,00 \mathrm{~kg}$ e $2,70 \mathrm{~kg} / \mathrm{ha}$ de MSMA, respectivamente com $0,20 \mathrm{~kg}, 0,30$ e $0,40 \mathrm{~kg} / \mathrm{ha} \mathrm{de}$ diuron, e de $0,60 \mathrm{~kg} / \mathrm{ha}$ de paraquat com $0,60 \mathrm{~kg} / \mathrm{ha}$ de diuron. Na aplicação precoce foi incluido ainda um tratamento com 1,75 $\mathrm{kg} / \mathrm{ha}$ de MSMA. Todos os herbicidas foram usados em suas formulações comerciais'. Constou do ensaio um tratamento testemunha, man tido livre da ocorrência de plantas daninhas por meio de capina à enxada.
As aplicações dos herbicidas foram feitas em pós-eme rgência, em jato dirigido, utilizando-se pulverizador costal pa ra 15 litros, manual, com agitador de calda, munido de um bi co «Polijet» verde, com protetor, com um gasto de calda corres pondende a 500 1/ha. $\mathrm{Na}$ aplicação precoce a altura média das plantas daninhas era de $0,10 \mathrm{~m}$ e na tardia, de 0,05 m. No mesmo dia da aplicação precoce as parcelas que iriam receber a aplicação tardia foram capinadas à enxada.

Para a avaliação dos tratamentos foi considerada a porcentagem de controle das plantas daninhas aos 7, 14 e 21 dias da aplicação dos herbicidas to ma da em re lação à in festação presente antes dessa aplicação. A amostragem qualitativa e quantitativa das plantas daninhas foi obtida em duas áreas de $0,50 \mathrm{~m} 2$ $(1,00 \times 0,50)$ por parcela, escolhidas ao acaso e posteriormente demarcadas.

A infestação natural das principais plantas daninhas era representada por: Digitaria sanguinalis, Acanthospermum australe, Richardia brasiliensis, Borreria alata e Sida spp.

Aos 21 dias da aplicação dos herbicidas fez-se uma avaliação visual de possíveis sinto mas de fi to to xi cidade sobre a cultura, uti lizando-se o seguinte sistema de notas:

1 - Total

2 - Forte

3 - Média

4 - Leve

5 - Nula

$\mathrm{O}$ «stand» e a produção de algo dão em caroço foram obtidas a 04/05/76.

\section{RESULTADOS E DISCUSSÃO}

Os resultados da porcentagem de controle das plantas daninhas são apresentados no quadro 1.
1 Carpurom Vertac - concentrado emulsioná- vel contendo $33,9 \%$ de MSMA e 5,1\% de diu- ron.
Paracol-emulsão - contendo $20,0 \%$ de pa- quat e $20,0 \%$ de diu- ron.
Daconate - concentrado emulsionável con- tendo $34,66 \%$ de MSMA. 
Quadro 1 - Porcentagem de controle de plantas daninhas nas très contagens realizadas em Casa Branca, SP, 1975/76

\begin{tabular}{|c|c|c|c|c|c|c|c|c|c|c|c|c|c|c|c|c|c|c|c|c|}
\hline \multirow{3}{*}{ HERBICIDAS } & \multirow{3}{*}{$\begin{array}{l}\text { INGREDIENTE } \\
\text { ATIVO } \\
(\mathrm{kg} / \mathrm{hal})\end{array}$} & \multirow{3}{*}{$\begin{array}{l}\text { EPOCA } \\
\text { DE } \\
\text { APLICACAOAO }\end{array}$} & \multicolumn{18}{|c|}{ PORCENTAGEM DE CONTROLE } \\
\hline & & & \multicolumn{3}{|c|}{$\begin{array}{l}\text { Digitaria } \\
\text { sanguinalis }\end{array}$} & \multicolumn{3}{|c|}{$\begin{array}{c}\text { Acanthospermum } \\
\text { australe }\end{array}$} & \multicolumn{3}{|c|}{$\begin{array}{l}\text { Richardia } \\
\text { brasiliensis }\end{array}$} & \multicolumn{3}{|c|}{$\begin{array}{l}\text { Borreria } \\
\text { alata }\end{array}$} & \multicolumn{3}{|c|}{ Sida spp } & \multicolumn{3}{|c|}{ Controle ger al } \\
\hline & & & $\begin{array}{l}\text { Após } \\
7 \text { dias }\end{array}$ & $\begin{array}{c}\text { Após } \\
14 \text { dias }\end{array}$ & $\begin{array}{c}\text { Após } \\
21 \text { dias }\end{array}$ & $\begin{array}{l}\text { Após } \\
7 \text { dias }\end{array}$ & $\begin{array}{c}\text { Aposs } \\
14 \text { dias }\end{array}$ & $\begin{array}{c}\text { Após } \\
21 \text { dias }\end{array}$ & $\begin{array}{l}\text { Após } \\
7 \text { dias }\end{array}$ & $\begin{array}{l}\text { Após } \\
14 \text { dias } 2\end{array}$ & $\begin{array}{c}\text { Após } \\
21 \text { dias }\end{array}$ & $\begin{array}{l}\text { Apos } \\
7 \text { dias }\end{array}$ & $\begin{array}{l}\text { Após } \\
14 \text { dias }\end{array}$ & $\begin{array}{c}\text { Após } \\
21 \text { dias }\end{array}$ & $\begin{array}{l}\text { Após } \\
7 \text { dias }\end{array}$ & $\begin{array}{c}\text { Após } \\
14 \text { dias } 2\end{array}$ & $\begin{array}{l}\text { Após } \\
21 \text { dias }\end{array}$ & $\begin{array}{l}\text { Após } \\
7 \text { dias }\end{array}$ & $\begin{array}{c}\text { Após } \\
14 \text { dias }\end{array}$ & $\begin{array}{c}\text { Após } \\
21 \text { dias }\end{array}$ \\
\hline MSMA + diuron & $1,35+0,20$ & Precoce & 48,5 & 52,3 & 66,2 & 97,6 & 99,6 & 99.6 & 84,5 & 88,2 & 88,2 & 75,2 & 83,2 & 92,0 & 77,3 & 85,7 & 91,6 & 77,1 & 77,4 & 86,7 \\
\hline MSMA + diuron & $2,00+0,30$ & Precoce & 54,1 & 76.9 & 81,2 & 98,3 & 99,1 & 99.6 & 82.3 & 85.8 & 93.8 & 69,1 & 86,4 & 90,1 & 73,6 & 83,0 & 90,6 & 73,6 & 86,0 & 90,0 \\
\hline MSMA + diuron & $2,70+0,40$ & Precoce & 59,9 & 88.1 & 94,6 & 100,0 & 100,0 & 100,0 & 92,8 & 94,6 & 96.4 & 74.7 & 97,5 & 97,5 & 86,0 & 88,4 & 93.0 & 77,8 & 92,7 & 96,2 \\
\hline MSMA + diuron & $1.35+0.20$ & Tardia & 44,3 & 56.4 & 63,7 & 100,0 & 100.0 & 100,0 & 100,0 & 100,0 & 100,0 & 100,0 & 100,0 & 100,0 & 69,8 & 73,9 & 73,9 & 68,5 & 74,9 & 78,4 \\
\hline MSMA + diuron & $2,00+0,30$ & Tardia & 82,4 & 90,6 & 93,4 & 100,0 & 100.0 & 100,0 & 100,0 & 100,0 & 100,0 & 100,0 & 100,0 & 100.0 & 95,3 & 97,7 & 97.7 & 91,2 & 95,3 & 96,7 \\
\hline MSMA + diuron & $2,70+0,40$ & Tardia & 95,5 & 98,2 & 98,8 & 100,0 & 100,0 & 100,0 & 100,0 & 100,0 & 100.0 & 100,0 & 100.0 & 100,0 & 100,0 & 100,0 & 100,0 & 97.8 & 99,1 & 99,4 \\
\hline Paraquat + diuron & $0,60+0,60$ & Precoce & 98,7 & 98,7 & 100,0 & 100,0 & 100,0 & 100,0 & 99.3 & 99,3 & 100,0 & 93.5 & 97,8 & $100,0 \quad 1$ & 100,0 & 100,0 & 100,0 & 98,4 & 99,0 & 100,0 \\
\hline Parequat + diuron & $0,60+0,60$ & Tardia & 99,3 & 99,31 & 100,0 & 100,0 & 100.0 & 100,0 & 100,0 & 100,0 & 100.0 & 100,0 & 100,0 & $100,0 \quad 1$ & 100,0 & 100,0 & 100,0 & 99,8 & 99,8 & 100,0 \\
\hline MSMA & 1,75 & Precoce & 48,5 & 55,7 & 69,5 & 75.4 & 86,5 & 87,1 & 47,9 & 71.4 & 72,4 & 43,7 & 43,7 & 66,2 & 49,5 & 62,4 & 63,4 & 55,8 & 63,8 & 76,6 \\
\hline \multicolumn{21}{|c|}{ Número medio de plantas daninhas por $\mathrm{m}^{2}$} \\
\hline antes da aplicaç̄o p & ecoce & & & 350 & & & 219 & & & 142 & & & 105 & & & 86 & & & 902 & \\
\hline \multicolumn{21}{|c|}{ Nümero médio de plantas daninhas por $\mathrm{m}^{2}$ antes da } \\
\hline aplicaçäo tardia & & & & 248 & & & 68 & & & 111 & & & 61 & & & 75 & & & 563 & \\
\hline
\end{tabular}


Observa-se que houve maior incidência da gramínea D. sanguinalis. com 38,8\% da inf estação geral na data da aplicação precoce, e 44,0\%, na da tardia. Porém, as quatro ervas de folhas largas que apareceram no ensaio, se agrupadas, perfazem uma infestação de $61,2 \%$ e $56,0 \%$ na aplicação precoce e na tardia respectivamente. Como era esperado $(11,13,14), D$. sanguinalis não fo i bem controlada pelas doses menores da mistura de MSMA e diuron; mas, as maiores controlaram-na muito bem. A mistura de paraquat com diuron também foi eficiente contra essa gramínea.

As quatro dicotiledôneas presentes foram melhor controladas pelas misturas de 2,00 $\mathrm{kg} / \mathrm{ha}$ e $2,70 \mathrm{~kg} / \mathrm{ha}$ de MSMA com $0,30 \mathrm{~kg} /$ ha e $0,40 \mathrm{~kg} / \mathrm{ha}$ de diuron, respectivamente; e por $0,60 \mathrm{~kg} / \mathrm{ha}$ de paraquat com $0,60 \mathrm{~kg} / \mathrm{ha}$ de diuron, com índices superiores a $90,0 \%$ de controle geral. Normalmente têm sido em pregadas doses maiores do que $1,00 \mathrm{~kg} / \mathrm{ha}$ de diuron em cultura algodoeira $(5,7,15,16)$. Porém, bons resultados têm sido obtidos com doses menores, ao redor de $0,50 \mathrm{~kg} / \mathrm{ha}(2$, $4,7,9)$, principalmente quando usado em misturas ou aplicações combinadas com ou tros herbicidas, confirmad os pelos resultados deste experimento onde doses menores ainda of ereceram eficiente controle das plantas infestantes.

MSMA, a 1,75 kg/ha, controlou eficientemente apenas A. australe. Em en saios conduzidos por Santos et al. (13) em 1965, em solos com $1,1^{\circ} \mathrm{k}, 1,2 \%$ e $1,7 \%$ de matéria or gânica, MSMA, a $1,80 \mathrm{~kg} / \mathrm{ha}$, controlou D. sanguinalis, porém não conseguiu um eficiente controle das outras gramíneas do ensaio com capim-pé-de-galinha (Eleusine indica (L) Gaertn) e capim-carrapicho (Cenchrus echinatus L). Melhores resultados têm sido encontrados com maiores doses de MSMA. o controle de apenas $63,4 \%$ de Sida spp por
MSMA confirma resultados obtidos por Frans \& Blythe (8) nos Estados Unidos, mesmo usando doses mais elevadas.

Após 21 dias da aplicação, tanto precoce como tardia, os tratamentos com paraquat + diuron apresentaram $100 \%$ de controle geral.

Somente os tratamentos com $1,35 \mathrm{~kg} / \mathrm{ha}$ de MSMA + 0,20 kg/ha de diuron, nas aplicações precoce e tardia, e com $1,75 \mathrm{~kg} / \mathrm{ha}$ de MSMA, precis aram de capinas adicionais até a colheita. A testemunha sem herbicida foi capinada três vezes.

O resultado de notas dadas para sintomas de fitotoxicidade, observados 21 dias após a aplicação, estão no quadro 2. Os tratamentos com diuron causaram clorose nos algodoeiros, mais in tensa nos tratamentos com paraquat do que com MSMA. Abernathy \& Ray (1), já em 1973, encontra ram re dução de fi to toxi cidade causadas por herbicidas à ba se de uréia e uracil quando aplicados em mistura com MSMA. Nos tratamentos com paraquat, na aplicação precoce somente, apareceram ainda, nas folhas, queimaduras localizadas, provocadas por deriva do produto.

MSMA, confirmando resultados obtidos por Abernathy \& Ray (1), apresentou um aumento de pigmentação vermelha de ramos, pecíolos e folhas, mais intensos quando aplicado isolado, porém sem interferir na produção de algodão. Kleyfeld \& Sachs (10) també $m$ não en contra ram redução de produção quando MSMA foi aplicado até duas vezes; porém, qua ndo es se he rbicida foi aplicado três vezes consecutivas, foi prejudicial à produção de algodão. Os demais tratamentos também não prejudicaram o «stand», o desenvolvimento vegetativo dos algodoeiros e sua produção. As médias dos dados de stand trans-

formados para $\mathrm{V}$, e as médias dos dados originais de produção de algodão em caroço (Quadro 2) , foram analisadas estatisticamente 
Quadro 2 - Fi to toxicidade 1, mé dia de «sta nd» com dados transformados para $\sqrt{(x)} \mathrm{e}$ média de dados originais de produção de algodão em caroço em Casa Branca, SP, 1975/76.

\begin{tabular}{|c|c|c|c|c|c|c|}
\hline HERBICIDAS & & $\begin{array}{c}\text { INGREDIENTE } \\
\text { ATIVO } \\
\mathrm{kg} / \mathrm{ha})\end{array}$ & $\begin{array}{l}\text { EPOCA DE } \\
\text { APLICACAO }\end{array}$ & $\begin{array}{l}\text { FITOTOXICI- } \\
\text { DADE }\end{array}$ & $\begin{array}{l}\text { eSTAND, } \\
\text { Transt. } \sqrt{(\mathbf{x})}\end{array}$ & $\begin{array}{c}\text { PRODUCXO } \\
\text { MEDIA } \\
\mathbf{k g}\end{array}$ \\
\hline MSMA + diuron & & $1,35+0.20$ & Precoce & 4,0 & 10,4 & 1,8 \\
\hline MSMA + diuron & & $2,00+0,30$ & Precoce & 3,5 & . $\quad 10,7$ & 1,7 \\
\hline MSMA + diuron & & $2.70+0.40$ & Precoce & 3.5 & 10,4 & 1,7 \\
\hline MSMA + diuron & & $1,35+0.30$ & Tardia & 5,0 & 10,5 & 1,7 \\
\hline MSMA + diuron & & $2.00+0.30$ & Tardia & 5,0 & 10,5 & 1,7 \\
\hline MSMA + diuron & & $2,70+0.40$ & Tardia & 5,0 & 10,9 & 1,7 \\
\hline Paraquat + diuron & & $0,60+0,60$ & Precoce & 3,0 & 10.4 & 1,7 \\
\hline Paraquat + diuron & & $0,60+0,60$ & Tardia & 5,0 & 10,8 & 1,8 \\
\hline MSMA & & 1,75 & Precoce & 4,5 & 10.5 & 1,9 \\
\hline Testemunha & & & & 5,0 & 10.9 & 1,7 \\
\hline C. V. (\%) & 3,97 & 20,55 & & & & \\
\hline P. & n. $\mathrm{s}$. & n. $\mathrm{s}$ & & & & \\
\hline
\end{tabular}

${ }^{1}$ Após 21 dias da aplicaçăo dos herbicidas.

pelo método da variância e os resultados não mostraram diferenças para tratamentos.

A capina à enxada, com revolvimento superficial do solo, na ocasião da aplicação precoce, não favoreceu a produção da aplica rão tardia.

\section{LITERATURA CITADA}

1 - ABERNATHY, J. R. \& RAY, L- L .Using MSMA to reduce dituron induced toxicity in cotton: Annual Meet. Southern Weed Sci. Soc., 27 th, Lubbock, USA, 1974, Proceedings, \%. 121.

2 - AHLAWAT, I. P. S. Comparative efficien cy of various herbicides and cultural me. thods in controlling weeds in cotton ficlds. Indian Journal of Weed Science 5 (2):155. 61,1974 .

3 - ALVES, A. \& FORSTER, R. Variações nos métodos de aplicação dos herbicidas diuron e trifluralin na cultura do algodoeiro. In Sem. Bras, Herb. Ervas Dan., 6.", Sete Lagoas, 1966. Anais. p. 51-63.

4 - ARLE, H. F. \& HAMILTON, K. C. Over the-top Aplications of Herbicides in Cotton Weed Science 24 (2) : 166.9, 1976.
5 - BUENDIA, J, P. L. \& BARROS A. T Competição de misturas de herbicidas na cultura algodoeira (Gossypium hirsutum L.) nas principais regiōes produtoras de Minas Gerais, In: Sem. Bras. Herb. Ervas Dan., 11. Londrina, 1976. Resumos, p. 42

6 - CRUZ, L. S. P. \& Leiderman, L. Pri. meiros estudos comparativos do efeito her bicida de fluchloralin e dinitramine para algodoeiros. Biológico 40 (11):314-20, 1974

7 - CRUZ, L. S. P. Aplicação de herbic' das em pós-emergência nas entre-linhas de a'go djeiros. In: Sem. Bras. Herb. Ervas Dan., $10 .{ }^{\circ}$, Santa Maria, 1974. Resumos, p. 37.

8 - FRANS, R. E. \& BLYTHE, T. O. Herbi clde field evaluation trials on field crops 1973. University of Arkansas, Agric Exp St., 1974, n." 218, 28 p. Mimeo.

9 - HONDA, T.; MACHADO, P R. \& POM PEU, R. M. Controle de ervas daninhas de folhas largas na cultura do algodão (Gos sypium hirsutum L.). In: Sem. Bras. Herb Ervas, Dan., 11. Londrina, 1976. Resu. mos, p. 41 .

0 - KLEYFELD, Y. \& SACHS, Y, Effect of dalapon and MSMA on irrigated cotton In: Conf. Weed Soc. of Israel, $5^{\text {th }}, 1973$ Proceedings, p. 21. 
11 - LELDERMAN, L.; CAMPOS, C. A. L.; FI. GUEIREDO, P. \& SILVEIRA, R. I Controle de ervas daninhas do algodão com misturas de Trifluralin e Diuron em quatro regiōes de São Paulo. Biológico, 32 (7): 158.62, 1966.

12 - LEIDERMAN, L. \& SANTOS, C. A. L. Aplicaçẫo de herbicidas, em pré-plantio, na cultura do algodão. In: Sem. Bras. Herb. Ervas Dan., 7.' Pelotas, 1968, Resumos.

13 - SANTOS, C. A. L.; LEIDERMAN, L. \& FIGUEIREDO, P. Ensaios comparativos entre Cotoran, novo herbicida à base de Uréia, Diuron e Trifluralin na cultura do algodắo. Biológico, 34 (1) : 12-16, 1968.

14 - SANTOS, C. A. L. \& HERTWIG, K. von.
Emprego de herbicidas de após-emergên. cia na cultura od algodão. Biológico, 36 : $307-10,1970$.

I5 - SHERIFF, R. A.; HUNSIGI, G. \& SASTRY, K. S. K. Weed control in cotton (Gossypium hirsutum L.) by herbicides and their residual toxicity to suceeding crops. Mysore Journal of Agriculture Sclence 7 (4) :588-96, 1973.

16 - VICTORIA Filho, R; CRUZ, L. S. P. \& GARCIA, I. Comportamento de misturas de dinitramine e diuron em pré-plantio in. corporado na cultura do algodâo (Gossy. pium hirsutum L.). In: Sem. Bras. Herb. Ervas Dan., 11.', Londrina, 1976. Resumos, p. 39. 